\title{
THE ANALYSIS OF TELECOM OPERATOR'S REVENUE DEPENDENCE ON DIFFERENT ROUTING AND INTERCONNECTION CHARGING METHODS
}

\author{
Aleksandra Kostić-Ljubisavljević́ ${ }^{1}$, Snežana Mladenović ${ }^{2}$, \\ Vladanka Aćimović-Raspopović $^{3}$
}

Faculty of Transport and Traffic Engineering, University of Belgrade, Vojvode Stepe 305, 11000 Belgrade, Serbia

E-mails: ${ }^{1} a . k o s t i c @ s f . b g . a c . r s$ (corresponding author); ${ }^{2}$ snezanam@sf.bg.ac.rs; ${ }^{3}$ v.acimovic@sf.bg.ac.rs

Received 07 February 2011; accepted 21 August 2011

\begin{abstract}
Telecommunication operators endeavour to offer their users numerous services and, at the same time, to be competitive with other operators at the market while accomplishing high revenue. The only way to achieve all those goals is to make better usage of their network resources and realise high network efficiency. In this paper, we tested the assumption that a proper combination of the different dynamic telecommunication traffic routing methods and interconnection charging methods can provide higher operators revenue. In order to analyze the effects of combinations of four different routing and two interconnection charging methods on operator's revenue, we developed new software for simulation of network operations. This software is used for simulation of the three interconnected networks operators. Results considering the dependence of operator's revenue on routing and interconnection charging methods combination are analyzed and discussed.
\end{abstract}

Keywords: Interconnection charging, dynamic routing of telecommunication traffic, telecommunications network, operator's revenue.

Reference to this paper should be made as follows: Kostić-Ljubisavljević, A.; Mladenović, S.; Aćimović-Raspopović, V. 2012. The analysis of telecom operator's revenue dependence on different routing and interconnection charging methods, Technological and Economic Development of Economy 18(4): 608-622.

JEL classification: C63, C88, L86, L96. 


\section{Introduction}

Network optimization has always been a core problem domain in telecommunications engineering and management, as well as in operations research, computer science, applied mathematics, and many other fields of engineering and management.

In order to assure a satisfactory level of network performance, telecommunication operator needs to apply a robust and fast network management. Network management refers to the activities, methods, procedures, and tools that pertain to the operation, administration, maintenance, and provisioning of networked systems (Clemm 2007). One of the main goals of network management is to make operations more efficient and operators more productive. There are many aspects of telecommunication network management covering wide range of disciplines from telecommunications to organization management, as well as from motivation to quality control and software reliability engineering. (Sherif 2006). Some of them are project management, scope management, time and cost management, information and communication management, resource management, quality management, vendor management, risk management, policy management etc. Many authors researched characteristics of project management (Zavadskas et al. 2012; Brauers, Zavadskas 2010) researched project management for transition economies. (Stukalina 2010) studied some aspects of quality management. (Raslanas et al. 2010) examined some aspects of the policy management. Strategic management was presented in (Saparauskas et al. 2011).

The interconnection of telecommunication operators enables them to deliver numerous services with high quality to their end users worldwide. The competition in telecommunication market induces them to achieve network efficiency and to optimize the use of their network resources. Otherwise, they will not have adequate revenue that allows them to invest in infrastructure, which enables them to offer all the services their users request. Also, they must bear in mind that users demand certain quality of service together with acceptable price.

The way that the interconnection charging is defined among operators is of great significance for the process of creating the tariffs for services that end user pays, and it affects the overall business of an telecommunications operator. That is the reason why the interconnection charging principle is one of the important research issues.

There are many concepts of determining proper and reasonable price of interconnection from operator's and regulator's point of view (ITU-D Question 6-1/1 2006; Armstrong 1998; Armstrong 2004; Berger 2005; Cambini, Valeletti 2003; Cavea, Vogelsang 2003; Falch 2002). Some of them are cost-based, bill-and-keep, revenue sharing, retail minus, price cap methods etc. The research presented in this paper is carried out by applying two most commonly used interconnection charging methods: bill-and-keep and cost-based.

In order to increase their revenue, telecommunications operators should pay special attention to the optimization of network operations. The goal of the research presented in this paper is to verify our hypothesis that properly selected combination of the interconnection charging and dynamic telecommunications traffic routing methods can significantly affect the optimization of network resources usage, and therefore result in increasing of the operator's revenue. 
Dynamic routing of telecommunications traffic is the convenient way of adjusting to frequent changes in intensity and traffic distribution among significant network resources. The introduction of dynamic routing into telecommunications networks can significantly improve network connection availability while simultaneously reducing network costs (Ash 1998). Unlike the methods with fixed routing rules in which the network capacities are allocated in accordance to forecasted traffic demands between pairs of switching nodes, dynamic routing is based on a different approach: traffic is assigned to those paths where free links are available. In this paper, we consider the term "link" as the bond between two telecommunication nodes, and the term "path" as the sequence of successive links connecting an origin and destination node. Furthermore, appropriately chosen dynamic traffic routing method allows better use of available resources and therefore substantial savings in network investment costs can be achieved. In addition to savings, there are other advantages of the dynamic routing compared to fixed routing that are discussed in (Ash 1998; Pioro, Medhi 2004).

Our research addresses the following dynamic routing methods: the shortest path, the three-hop, the random path and the last successful path routing. The short description of the tested routing methods and their notification will be given in next section. The problem statement is given in section 2. To achieve our research we developed a_special software for telecommunications traffic simulation for different routing and interconnection charging methods, which will be presented in section 3. The section 4 presents analysis of the obtained results. Finally, some concluding remarks are given.

\section{Problem statement}

Let us consider the situation in which three telecommunication network operators $\mathrm{A}, \mathrm{B}$, and $\mathrm{C}$ are interconnected as shown in Figure 1. The operators $\mathrm{A}, \mathrm{B}$ and $\mathrm{C}$ could be considered as the incumbent operator (B) and new entrants (A and C). The distribution of their corresponding nodes and links is given in Table 1.

The network model is based on the real telecommunication transport network of the Republic of Serbia. For the purpose of telecommunications operator's revenue analysis, we applied four different routing methods in combination with two interconnection charging methods.

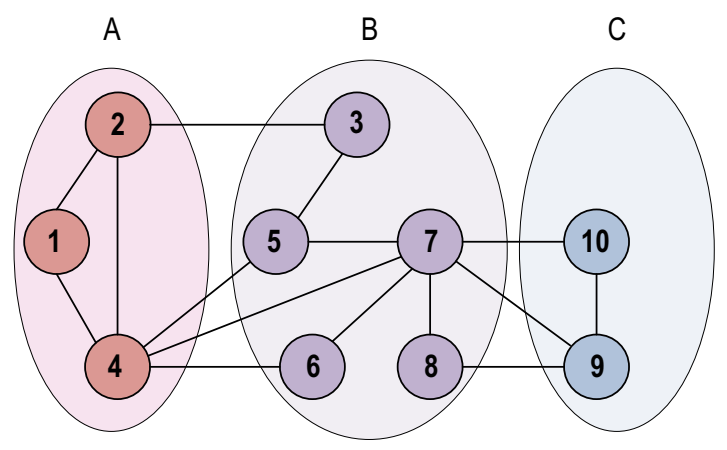

Fig. 1. Network configuration of operators A, B and C 
Table 1. Distribution of network links and nodes between interconnected operators

\begin{tabular}{cccc}
\hline & Operator A & Operator B & Operator C \\
\hline Links & $1-2,1-4,2-4$ and $4-5$ & $2-3,3-5,4-6,4-7,5-7,6-7$ and 7-8 & $7-9,7-10,8-9$ and $9-10$ \\
\hline Nodes & 1,2 and 4 & $3,5,6,7$ and 8 & 9 and 10 \\
\hline
\end{tabular}

Bill-and-keep approach means that operators do not charge each other for interconnection service. Each operator bills its end users in accordance with the output traffic it generated, and keeps all income arising from it. This method assumes that if there were interconnection payments, they would roughly cancel each other out, resulting in no real net gain or loss for either carrier. Further, by forgoing payments, carriers avoid the administrative burden of billing one another for exchanged traffic (ITU-D Question 6-1/1 2006). The bill-and-keep method is the most appropriate in situations where the traffic between operators is roughly in balance. Otherwise, one of the operators will have revenue losses because of greater traffic termination in its network. It is estimated that the bill-and-keep will have its application also in the next generation networks (Dodd et al. 2009).

Cost-based approach implies that the interconnection tariff is formed in a way to achieve operator's cost recovery. The major disadvantage of this approach is the problem of proper (and precise) determination of interconnection costs. Namely, in the business of telecommunications operators, it is very hard precisely to determine those costs that are formed in the process of interconnection. This approach is one of the most accepted among telecommunications operators and regulators around the world. There are numerous realizations and approaches for adequate cost assessment (Kostić-Ljubisavljević et al. 2007; Noumba et al. 2004; Zheng et al. 2011, Lai 2012).

There is a very large number of different dynamic routing methods whose primary goal is to optimize the network performance by better utilization of its resources (Ash 1998), (Pioro, Medhi 2004; Gunnar, Johansson 2010). Shortest path routing is a well known method with many possible applications in different telecommunication networks (Pioro, Medhi 2004; Kwon, Shroff 2009; Kumari, Geethanjali 2010; Saad, Luo 2006), therefore it is not described in detail. This routing method will be represented as "spr" in the following of the paper. The three-hop routing method is the technique of carrying connection requests along paths that contain no more than three links. The three-hop routing is explained in more detail and one of its possible applications is presented in (Shen 2009). This routing method will be marked as "thr". The random path routing means routing along paths that are selected randomly from all possible paths between originated and terminated node, and it will be assigned in this paper as "rpr". One of many methods from the self-learning group is the last successful path routing and one of its applications is given in (Chao et al. 2009). With the term "lspr" the last successful path routing will be considered, as the routing method based on memorizing the path by which the last connection request between observed pair of nodes has been carried. The bill-and-keep interconnection charging method will be represented as the added " $b$ " to the notification of the applied routing method (e.g. " $r p r-b$ " means that the random path routing with bill-and-keep interconnection charging method was applied). The cost-based method will be marked as additional " $c$ " to the notification of the applied routing method. 
The observed network is characterized by the following data: (1) the link capacity, (2) the link cost, (3) the node capacity and (4) the node cost. We assumed that all links in the network have equal capacity. The link cost is defined as the cost of the operator for carrying connection that is originated, transits through, or it is terminated in the network. In this paper, we introduced the "cost factor of interconnection". This factor multiplies the link cost in case when link is used for carrying traffic originated or/and terminated in interconnected networks.

The term node capacity is considered here as an average number of connection requests that can be generated at any node. The node capacity is normalized to one. It can be defined according to the population of related geographic area, their level of education, age, profession etc. We assumed that if links entering and leaving the node are free, each node could forward all transit traffic. Each node is generating connection requests, which are represented by the Poisson process (Teletraffic 2008) with a mean value as the multiple of pre-defined capacity of the node. The Poisson process is a stochastic process in which events occur continuously and independently of one another.

In probability theory and statistics, the Poisson process is described with the Poisson distribution. This distribution is a discrete probability distribution that expresses the probability of a number of events occurring in a fixed period of time if these events occur with a known average rate and independently of the time since the last event. The Poisson distribution can be applied to systems with a large number of possible outcomes, each of which is rare. The Poisson distribution can also be used for the number of events in other specified intervals such as distance, area or volume (Har 2008). If the expected number of occurrences in this interval is $\lambda$, then the probability that there are exactly $k$ occurrences is equal to

$$
f(k, \lambda)=\frac{\lambda^{k}}{k !} e^{-\lambda}, k=0,1,2,3 \ldots,
$$

where $k$ is a non-negative integer, $k=0,1,2, \ldots$ denotes the number of occurrences of an event - the probability of which is given by the function. The parameter $\lambda$ is a positive real number, equal to the expected number of occurrences that occur during the given interval. This parameter is called the intensity or rate.

The node cost is a parameter that represents the cost of forwarding connections through the observed node. Depending on a function of a given node, the cost can be related to generation, transition and termination of a connection. For all nodes, we assumed that the costs of generating and termination of a connection are equal. The cost of transition is the half of generation and termination cost.

The term connection here will be concerned as an end user request for bundle of services offered by an operator. Bundle of services presents a group of selected broadband services, as defined in (RATEL 2008). In that document, the term broadband access, which should be provided for each end user, means the permanent access to the resources of telecommunications networks with bit rates not less than $4 \mathrm{Mb} / \mathrm{s}$. End users are grouped around the observed nodes in the network. Duration of connection has the exponential distribution with predefined mean value. The exponential distribution is a family of continuous probability distribution. It describes the time between events in the Poisson process, i.e. a process in 
which events occur continuously and independently at a constant average rate. The period, which is seven times longer than the mean duration of the connection, is simulated, while omitting from data analysis intervals that are equal to average duration of the connection at the beginning and end of the simulation. Duration of the connection is viewed as a random variable that has an exponential distribution (Iversen 2010).

\section{Software description}

As we already mentioned above, the main software task is a simulation of network operations with different interconnection charging methods under different routing methods. The result of this simulation should be comparison of those methods related to different performance parameters. This software was developed with the ability to change numerous inputs: network topology, node and link capacity, node and link cost, average number of traffic demands ... In order to obtain correct conclusions, it is necessary that they are derived after "enough" large number of experiments. Developed software simulates the handling of traffic demands in the telecommunications network and performs statistical processing of the relevant parameters.

In the structure of the software, which is shown in Figure 2, we can point out the following logical units: network initialisation, traffic demands generation, simulation of carrying traffic demands and statistical processing.

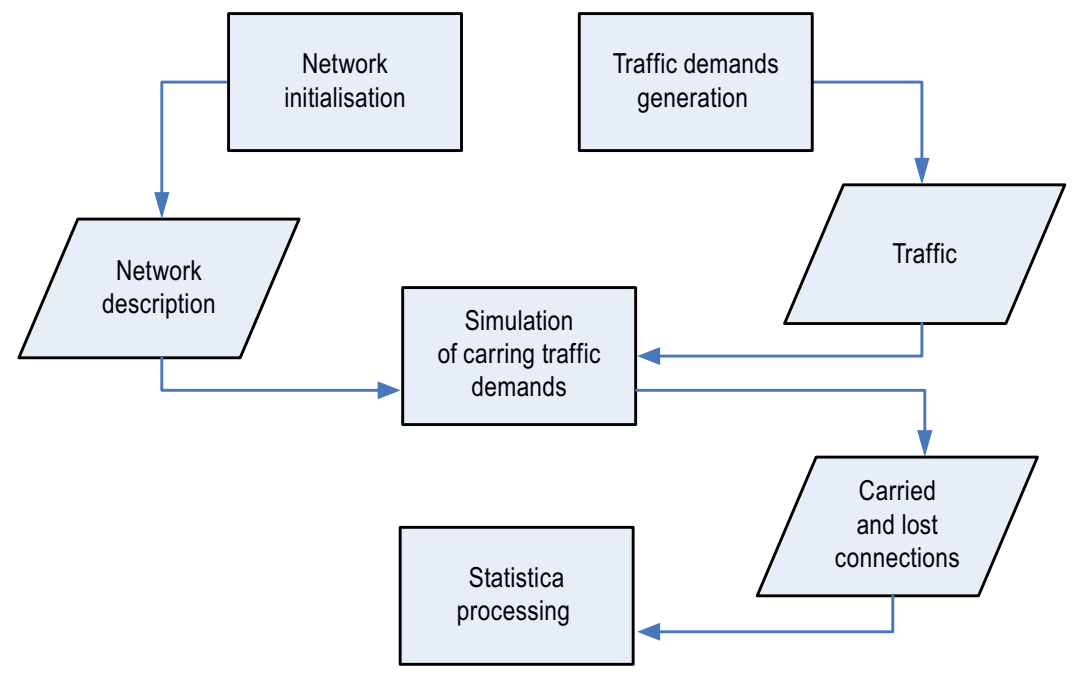

Fig. 2. Structure of the developed software

Network initialisation - In mathematical terms, the telecommunication network is represented as a graph. Node attribute is the node capacity and link attributes are the start and end node as well as the link cost. The main task of initialization unit is representation the actual network by data structures suitable for the simulation process. 
Traffic demands generation - For each node, connection requests are represented by the Poisson traffic, with a mean value as the multiple of pre-defined capacity of the node. The parameter related to the multiple of traffic intensity (from 0.5 to 5 ) is entered from input mask, and capacities of nodes are entered from the input file. Attributes of connection request are source node, destination node, moment of generation and duration.

Simulation of carrying traffic demands - For a given network and offered telecommunications traffic, the software user selects one of the offered methods of routing and one of the offered interconnection charging methods. In addition to these data, the charging rate for the bundle of services should also be chosen. The process of simulation after that can be activated. The connection can be carried or lost. "The track" about each carried or lost connection will be saved in an output file.

Statistical processing - The outputs from the previous stage give the possibility of forming a large number of statistics related to connections, nodes, links, paths, costs, and so on. For each offered traffic intensity, routing and interconnection charging method, and for each operator, statistic data are relating to:

- the number of connections that is generated, transited and terminated for each node in the network, and for each network operator,

- costs of connections,

- percentage of link usage,

- revenues obtained by carrying the connections,

- detailed information about number of connections that are terminated in each operators network as well as information about their origin,

- for each path that is used, the following issues are stored: all data of links forming a path, the number of connections that have used this path, as well as the time of usage,

- number of realized connections between node pairs,

- cumulative and average costs of realized connections between node pairs.

The spiral model of developed software, according to authors' opinion, is the model of the first choice for software development for this kind of applications. The software is developed incrementally, by developing a series of prototypes, that being verified and validated, considering our increasing requirements. In this stage of our research, the first prototype of the software has been realized. All logical units described above have been implemented as program assemblies in Microsoft Visual Basic environment.

The software system testing is carried out in a standard way through verification and validation according to the IEEE standard (IEEE 2004). The verification checks if the system has been built correctly (software internal quality) and the validation checks if the system as built is correct (software external quality). The first prototype of simulation software was assessed for all quality criteria, according to (Leach 2000). The specificity of the simulation software imposes to pay special attention to efficiency and modifiability. Efficiency of the software (reasonable runtime) gives possibility for a large number of experiments for a short time. For example, Table 2 presents duration of simulation (in seconds) on personal computer Intel Core 2 Duo CPU E8400 3 GHz, 3.49 GB RAM, under different multiple of 
traffic intensity (0.5-5), fixed number of channels per link (30) and fixed simulation period. These results show that simulation part of the realized software is efficient. Another software part has minor runtime in comparison with simulation. Modifiability is important for considering the new software user requirements (e.g. new methods of routing, new methods of interconnection charging) or improving some of the existing options. It is authors' plan for the next software prototype.

Table 2. Efficiency of developed software for all combination of routing and interconnection charging methods

\begin{tabular}{ccccccccc}
\hline $\begin{array}{l}\text { Multiple } \\
\text { of traffic } \\
\text { intensity }\end{array}$ & $s p r-b$ & $t h r-b$ & $r p r-b$ & $l s p r-b$ & $s p r-c$ & $t h r-c$ & $r p r-c$ & $l s p r-c$ \\
\hline 0,5 & 2 & 1 & 2 & 2 & 2 & 1 & 3 & 3 \\
\hline 1 & 4 & 2 & 5 & 6 & 5 & 1 & 5 & 5 \\
\hline 1,5 & 7 & 2 & 7 & 7 & 7 & 3 & 7 & 7 \\
\hline 2 & 10 & 3 & 9 & 10 & 10 & 3 & 10 & 10 \\
\hline 2,5 & 13 & 3 & 11 & 12 & 13 & 4 & 12 & 11 \\
\hline 5 & 16 & 5 & 14 & 13 & 15 & 5 & 14 & 13 \\
\hline 3,5 & 18 & 6 & 16 & 15 & 18 & 5 & 16 & 15 \\
\hline 4 & 21 & 6 & 19 & 18 & 20 & 6 & 19 & 19 \\
\hline 4,5 & 23 & 7 & 21 & 21 & 24 & 7 & 20 & 21 \\
\hline 5 & 24 & 7 & 21 & 23 & 24 & 7 & 21 & 23 \\
\hline
\end{tabular}

\section{Analysis of results}

As we have already mentioned above, only one of many possible analyses will be shown in this section, namely the analysis of operator's revenue. Extensive simulations have been carried out in order to get statistically correct data, which can further be analysed. We firstly observed and analysed how both considered interconnection charging methods influence operator's revenue, then we analysed routing method influence for each network operator.

In order to better notice the impact of interconnection charging methods on the operator's revenue, we performed detailed comparison of operator's revenue for every considered routing methods on the subject of interconnection. The obtained results for network operators A, B and C will be presented in Figures 3, 4 and 5, respectively.

Figure $3 \mathrm{a}, \mathrm{b}$ and $\mathrm{c}$ shows that the way of interconnection charging has significant influence on the operator A revenue for all traffic intensities and spr, thr and rpr. However, when applying $l s p r$, the selected interconnection charging method does not perform significant impact on the operator's revenue, especially for high traffic load, which is shown in Figure $3 \mathrm{~d}$.

Considering the results for the network operator B demonstrated in Figure 4, we notice that the bill-and-keep interconnection charging method enables greater operator's revenue. The interconnection charging method has small impact on the operator's revenue for low traffic intensity, by applying thr, and for all traffic intensities for $l s p r$. 
616 Aleksandra Kostić-Ljubisavljević et al. The analysis of telecom operator's revenue dependence ...

a)

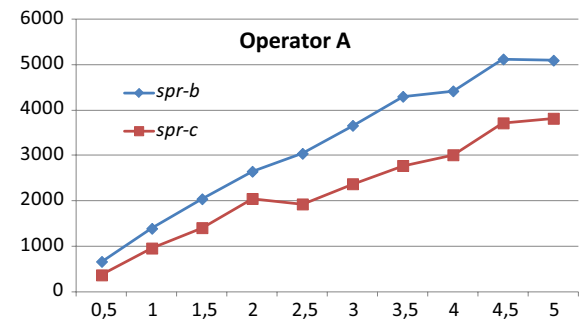

c)

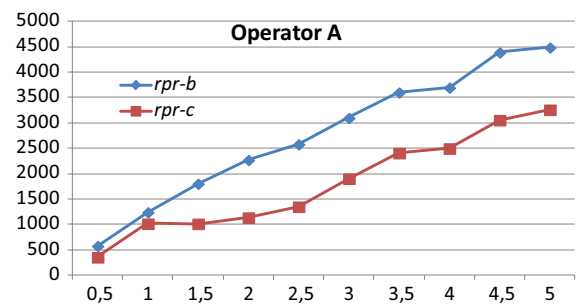

b)

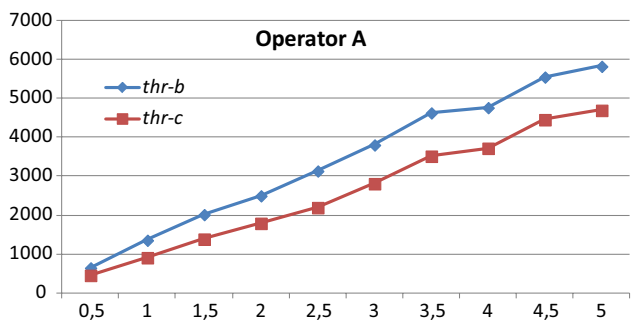

d)

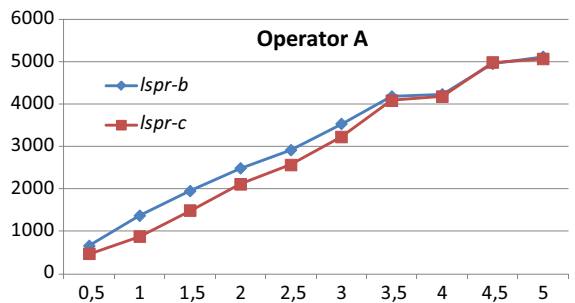

Fig. 3. Detailed comparison of operator's A revenue for each considered routing method on the subject of interconnection charging ( ${ }^{*}$ horizontal axis represents multiple of traffic intensity, while vertical axis represents operator's revenue in monetary units)

a)

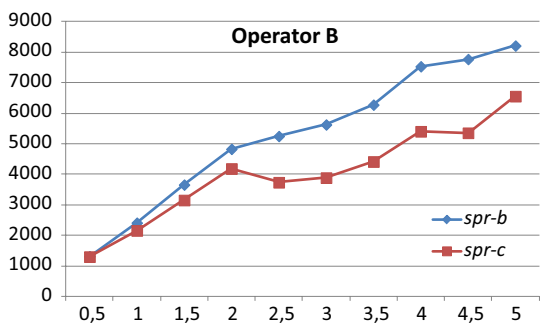

c)

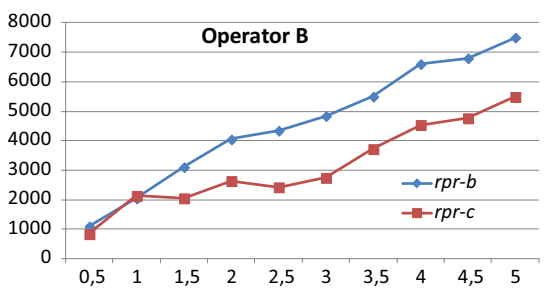

b)

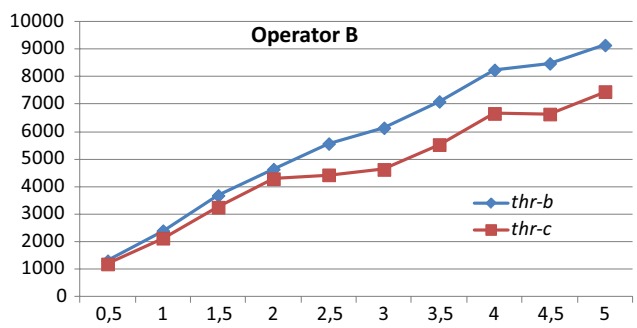

d)

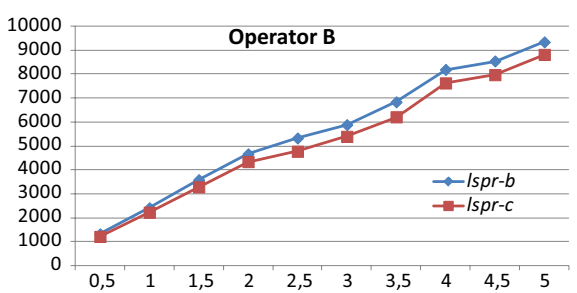

Fig. 4. Detailed comparison of operator's B revenue for each considered routing method on the subject of interconnection charging ( ${ }^{\star}$ horizontal axis represents multiple of traffic intensity, while vertical axis represents operator's revenue in monetary units) 
a)

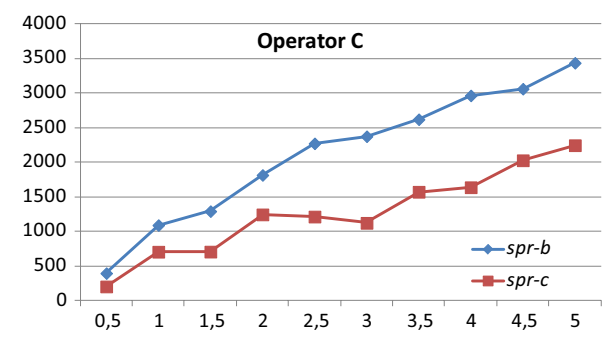

c)

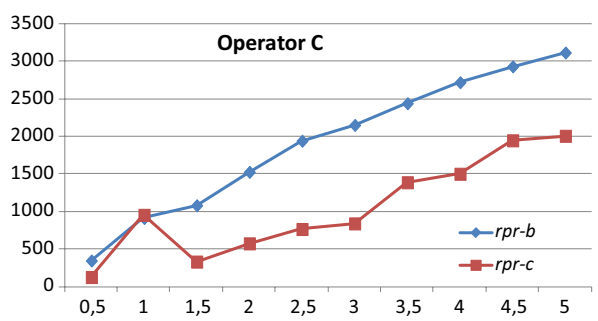

b)

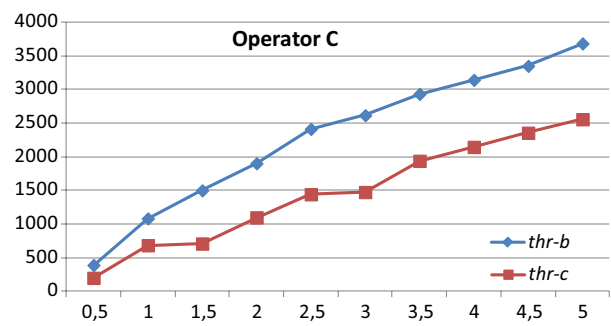

d)

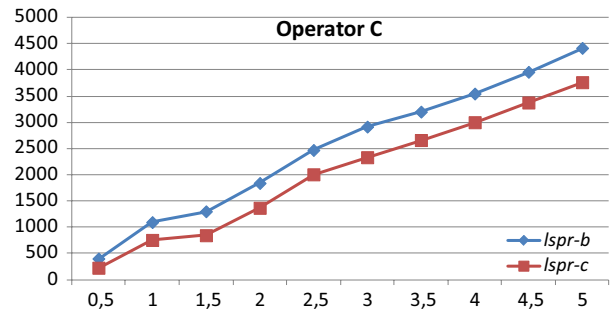

Fig. 5. Detailed comparison of operator's $C$ revenue for each considered routing method on the subject of interconnection charging ( ${ }^{*}$ horizontal axis represents multiple of traffic intensity, while vertical axis represents operator's revenue in monetary units)

Figure 5 illustrates the simulation results for the network operator C. As we have already noticed, the bill-and-keep method outperforms the cost-based interconnection charging method for each routing technique. It can be pointed out for lspr that the difference between those two interconnection methods is smaller, but slightly bigger than for other two operators.

Our further investigation is based on the detailed analysis of the impact of routing methods on the network operator's revenue. Figures 6, 7 and 8 illustrate the dependency of the operator's revenue for different routing methods with bill-and-keep and cost-based interconnection charging method, for network operators A, B and C, respectively.

It can be observed from Figure 6 a that there is a relatively small difference among operator's revenue for all considered routing methods. The revenues are almost the same for low traffic intensity, while for higher loads the thr shows slightly better performance with bill-and-keep interconnection charging. When applying the cost-based interconnection charging method, the lspr gives higher operator's revenue. For both interconnection charging methods, the $r p r$ achieves the lowest revenue.

Figure 7 shows the simulation results for different routing techniques for the network operator B. The thr and lspr methods are almost equal and better than others are, considering bill-and-keep interconnection charging, which is presented in Figure 7a. On the other hand, for the cost-based interconnection (Fig. 7b), the lspr method provides the best results for higher traffic load. 
Figure 8 illustrates the revenues for the network operator $\mathrm{C}$ taking into account four different routing methods. It can be noticed from Figure $8 \mathrm{a}$ that, when bill-and-keep interconnection was applied, the lspr yields the highest revenue comparing to others and the difference among them increases when the traffic load also increases. The lspr also outperforms others when cost-based interconnection is applied, which is significantly shown in Figure 8b.

a)

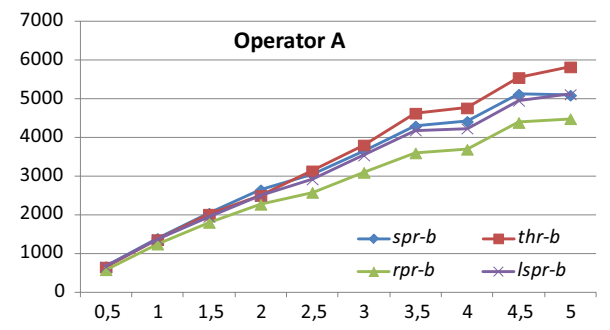

b)

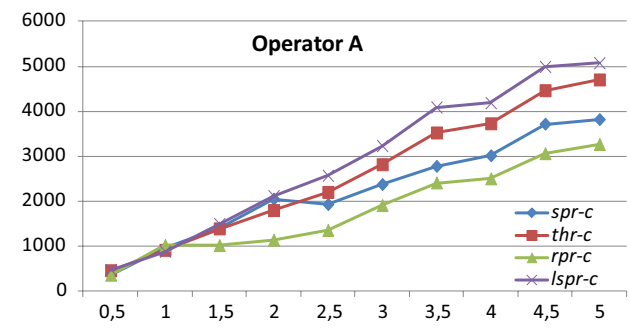

Fig. 6. Comparison of combinations of different routing methods with a) the bill-and-keep and b) the cost-based interconnection charging method, for network operator A. ( ${ }^{*}$ horizontal axis represents multiple of traffic intensity, while vertical axis represents operator's revenue in monetary units)

a)

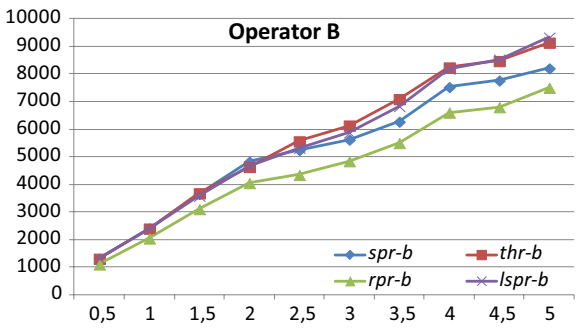

b)

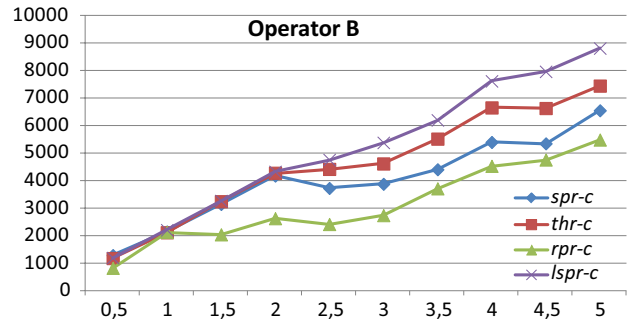

Fig. 7. Comparison of combinations of different routing methods with a) the bill-and-keep and b) the cost-based interconnection charging method, for network operator B. $\left({ }^{*}\right.$ horizontal axis represents multiple of traffic intensity, while vertical axis represents operator's revenue in monetary units)

a)

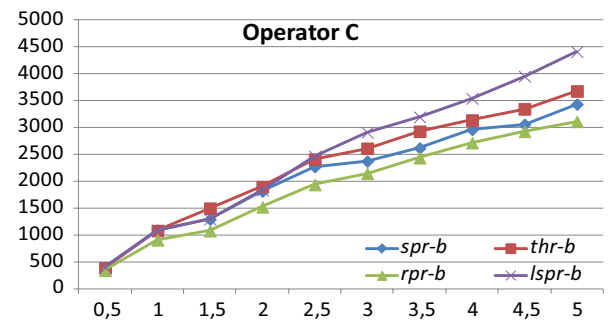

b)

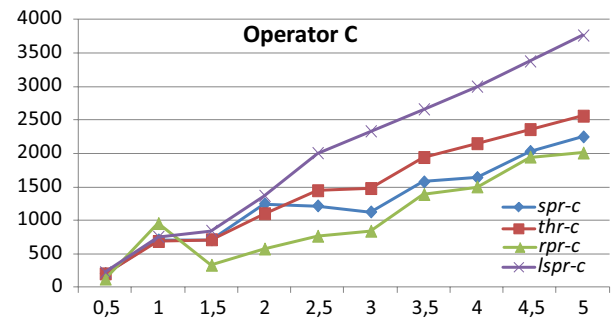

Fig. 8. Comparison of combinations of different routing methods with a) the bill-and-keep and $b$ ) the cost-based interconnection charging method, for network operator C. ( ${ }^{\star}$ horizontal axis represents multiple of traffic intensity, while vertical axis represents operator's revenue in monetary units) 
Figure $9 \mathrm{a}$ and $\mathrm{b}$ represents the illustrative example of simulation results carried out for applied spr for bill-and-keep and cost-based interconnection charging methods, respectively. The results for other routing methods are very similar, and therefore they will not be given in this paper. For each routing method, it can be concluded that the network operator B has the significantly greatest revenue. That is mainly because of the highest number of nodes (operator $\mathrm{A}$ has three, operator B has five and operator $\mathrm{C}$ has two nodes), which implies higher number of users who are paying for bundle of services they demand.

At the end of our analysis, we made graphical representation of dependence of operator's revenue for every operator relating to different routing and interconnection methods. It is shown in Figure 10a, b and c, respectively. One can observe from the Figure 10a that the network operator A has the biggest revenue for the $t h-b$ (three-hop routing and bill-and-keep

a)

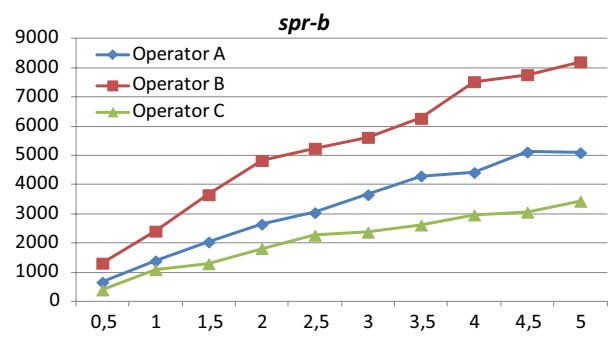

b)

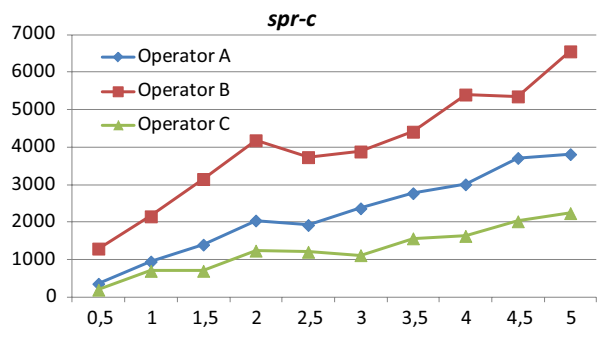

Fig. 9. Simulation results carried out for the shortest path routing method and for each network operator $\left({ }^{*}\right.$ horizontal axis represents multiple of traffic intensity, while vertical axis represents operator's revenue in monetary units)

a)

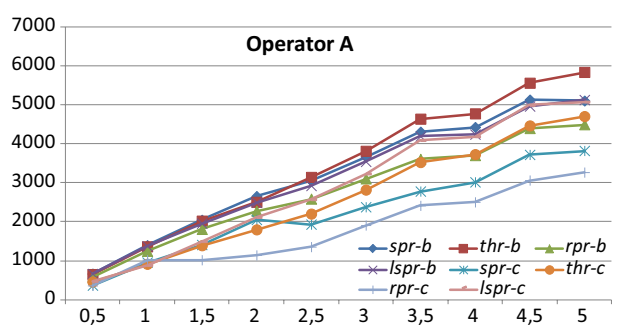

b)

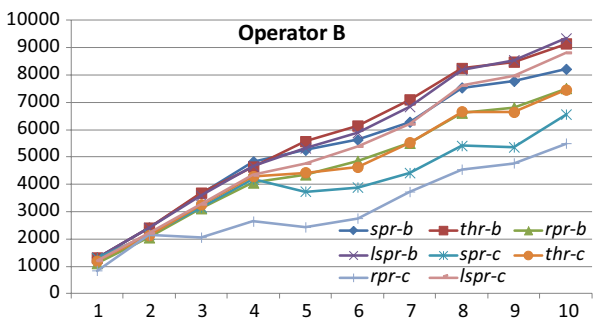

c)

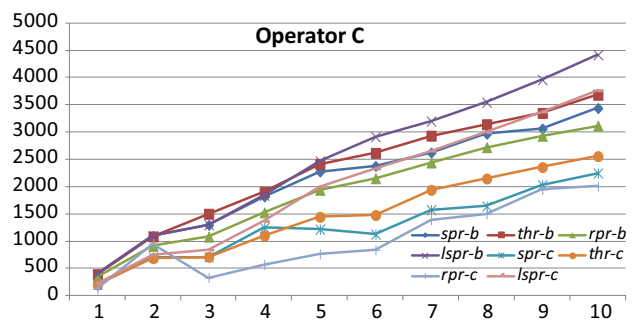

Fig. 10. Dependence of operator's revenue for each network operator relating to different routing and interconnection methods ( ${ }^{*}$ horizontal axis represents multiple of traffic intensity, while vertical axis represents operator's revenue in monetary units) 
interconnection). On the other side, the smallest revenue is obtained for the $r p r-c$ (random path routing with cost-based interconnection). Figure $10 \mathrm{~b}$ shows that for the operator $\mathrm{B}$ the methods thr-b and $l s p r-b$ (last successful path routing and bill-and-keep interconnection) yield almost equal revenues. On the contrary, the method $r p r$-c yields the smallest revenue. Another observation is that almost all methods give very similar revenues for low traffic intensity, for network operators A and B. Taking into account Figure 10c, we noticed that for operator $\mathrm{C}$ the method $l s p r-b$ outperforms others when the traffic intensity increases, and that $r p r-c$ provides the smallest revenue for almost all traffic intensities.

\section{Conclusions}

Telecommunications networks worldwide are interconnected with each other providing their end users all the services they offer at affordable price. To do so the telecommunication operators must find a way to optimize their network operations through better utilization of network resources. This will enable them to realize higher revenue. One of the possible ways to achieve that is the application of dynamic routing of telecommunication traffic. The main aim of our research is to find how dynamic routing and interconnection charging methods interact, and how they affect the operator's revenue.

In order to verify the influence of combined routing and interconnection charging methods on operator's revenue, we developed the new software for simulation of telecommunication network operations. We also performed simulation experiments with three interconnected operators in which we considered the joint impact of two methods of interconnection charging (bill-and-keep and cost-based) and four routing methods (the shortest path, the three-hop, the random path and the last successful path routing). Based on numerous simulation experiments and analysis, we found that the combination of the three-hop routing and bill-and-keep interconnection charging methods enables the greatest revenue for the operator A. Beside this, the combination of the last successful path routing and bill-and-keep interconnection, similarly, has the greatest impact for the operators B and C when the traffic intensity increases.

Modular concept of the developed software allows us to apply it on different network topology and distribution of network resource among several operators. Our further investigation will include the analysis of additional routing and interconnection charging methods, and their influence on operator's revenue. In addition, we will analyse other network performances and economical factors in order to obtain adequate combination of routing and interconnection charging methods that will lead to general optimization of network resources usage and growth of operator's revenue.

\section{Acknowledgements}

This work is partially supported by the Ministry of the Science and technological development of the Republic of Serbia with the project TR32025. 


\section{References}

Armstrong, M. 1998. Network interconnections in telecommunications, Economic Journal 108(448): 545-564. http://dx.doi.org/10.1111/1468-0297.00304

Armstrong, M. 2004. Network interconnection with asymmetric networks and heterogeneous calling patterns, Information Economics and Policy 16(3): 375-390.

http://dx.doi.org/10.1016/j.infoecopol.2004.01.006

Ash, G. R. 1998. Dynamic Routing in Telecommunication Networks. New York: McGraw' Hill. 746 p.

Berger, U. 2005. Bill-and-keep vs. cost-based access pricing revisited, Economics Letters 86(1): 107-112. http://dx.doi.org/10.1016/j.econlet.2004.07.003

Brauers, W. K. M.; Zavadskas, E. K. 2010. Project management by multimoora as an instrument for transition economies, Technological and Economic Development of Economy 16(1): 5-24. http://dx.doi.org/10.3846/tede.2010.01

Cambini, C.; Valletti, T. M. 2003. Network competition with price discrimination: 'bill-and-keep' is not so bad after all, Economics Letters 81(2): 205-213. http://dx.doi.org/10.1016/S0165-1765(03)00171-X

Cavea, M.; Vogelsang, I. 2003. How access pricing and entry interact, Telecommunications Policy 27(10-11): 717-727. http://dx.doi.org/10.1016/j.telpol.2003.08.004

Clemm, A. 2007. Network Management Fundamentals. Cisco Systems, Inc. 552 p.

Chao, D.; Yong, Z.; Yinglei, T.; Zhang, Z.; Jiansong, G. 2009. A self-learning multicast routing algorithm for multi-rate WiFi mesh network, in Proc. of 2 nd IEEE International Conference IC-BNMT '09, 18-20 October 2009, Beijing, China, IEEE, 513-518.

Dodd, M.; Jung, A.; Mitchell, B.; Paterson, P.; Reynolds, P. 2009. Bill-and-keep and the economics of interconnection in next-generation networks, Telecommunications Policy 33(5-6): 324-337. http://dx.doi.org/10.1016/j.telpol.2009.02.002

Falch, M. 2002. TELRIC - the way towards competition? A European point of view, Review of Network Economic 1(2): 147-154. http://dx.doi.org/10.2202/1446-9022.1011

Gunnar, A.; Johansson, M. 2010. Robust load balancing under traffic uncertainty - tractable models and efficient algorithms, Telecomunnication Systems 48(1-2): 93-107.

Hao, H. 2008. Poisson distribution and application [online], [cited September 2010]. Available from Internet: http://sces.phys.utk.edu/ moreo/mm08/Haohu.pdf

IEEE 2004. IEEE Standard 1012-2004 for Software Verification and Validation. C/S2ESC - Software \& Systems Engineering Standards Committee, 2004.

ITU-D Question 6-1, Report on interconnection [online] available from Internet: http://www.itu.int/publ/D-STG-SG01.06.1-2006

Iversen, V. B. 2010. Teletraffic engineering and network planning. [online], [cited October 2010]. Available from Internet: http://oldwww.com.dtu.dk/teletraffic/handbook/ telenook.pdf

Kostić-Ljubisavljević, A.; Radojičić, V.; Aćimović-Raspopović, V. 2007. An implementation of adaptable bottom-up model for calculation interconnection costs, in Proc. of XLII ICEST 2007, 24-27 June, 2007, Ohrid, Macedonia, 1: 177-180.

Kumari, M.; Geethanjali, N. 2010. A survey on shortest path routing algorithms for public transport travel, Global Journal of Computer Science and Technology 9(5): 73-76.

Kwon, S.; Shroff, N. B. 2009. Analysis of shortest path routing for large multi-hop wireless networks, Journal IEEE/ACM Transactions on Networking 17(3): 857-869.

Lai, J. H. K. 2012. Analytical assessment and comparison of facilities management services for residential estates, International Journal of Strategic Property Management 16(3): 236-253. http://dx.doi.org/10.3846/1648715X.2012.682183

Leach, R. J. 2000. Introduction to software engineering. Boca Raton, Florida: CRC Press. 445 p. 
Noumba, P.; Gille, L.; Simon, L.; Rudelle, C. 2004. A model for calculating interconnection costs in telecommunications. World Bank. 81 p. http://dx.doi.org/10.1596/0-8213-5671-2

Pioro, M.; Medhi, D. 2004. Routing, flow, and capacity design in communication and computer networks. San Francisco: Elsevier. 765 p.

Raslanas, S.; Zavadskas, E. K.; Kaklauskas, A. 2010. Land value tax in the context of sustainable urban development and assesment. Part I - Policy analysis and conceptual model for the taxation system on real property, International Journal of Strategic Property Management 14(1): 73-86. http://dx.doi.org/10.3846/ijspm.2010.06

Saad, M.; Luo, Z. Q. 2006. Design of WDM networks under economy of scale pricing and shortest path routing, IEEE Journal on Selected Areas in Communications 24(4): 26-36. http://dx.doi.org/10.1109/JSAC.2006.1613770

Saparauskas, J.; Zavadskas, E. K.; Turskis, Z. 2011. Selection of Facade's Alternatives of Commercial and Public Buildings Based on Multiple Criteria, International Journal of Strategic Property Management 15(2): 189-203. http://dx.doi.org/10.3846/1648715X.2011.586532

Sherif, M. H. 2006. Managing Projects in Telecommunication Services. New Jersey: John Wiley and Sons. 247 p. http://dx.doi.org/10.1002/0470047682

Shen, Z. L. H. 2009. A distributed three-hop routing protocol to increase the capacity of hybrid networks, in Proceedings of ICPP 09, September 22-25 2009, Vienna, 277-284.

RATEL 2009. Strategija razvoja širokopojasnog pristupa u Republici Srbiji do 2012 godine [Strategy of development of broadband access in the Republic of Serbia up to 2012, Goverment of Republic of Serbia]. [Online], [cited September 2010]. Available from Internet: http://www.mtid.gov.rs/upload/ documents/propisi/strategije/Strategija\%20i\%20akcioni\%20plan\%20razvoj\%20sirokopojasnog\%20 pristupa.pdf (original in Serbian)

Stukalina, Y. 2010. Using quality management procedures in education:managing the learner centered educational environment, Technological and Economic Development of Economy 16(1): 75-93. http://dx.doi.org/10.3846/tede.2010.05

Zavadskas, E. K.; Vainiūnas, P.; Turskis, Z.; Tamošaitienė, J. 2012. Multiple criteria decision support system for assessment of projects managers in construction, International Journal of Information Technology \& Decision Making 11(2): 501-520. http://dx.doi.org/10.1142/S0219622012400135

Zheng, X.; Chau, K.-W.; Hui, E. C. M. 2011. Efficiency assessment of listed real estate companies: an empirical study of China, International Journal of Strategic Property Management 15(2): 91-104. http://dx.doi.org/10.3846/1648715X.2011.582739

Aleksandra KOSTIĆ-LJUBISAVLJEVIĆ. PhD in Telecommunication traffic and networks, Assistant Professr, Department of Telecommunication traffic and networks, Faculty of Transport and Traffic Engineering, University of Belgrade, Serbia. Research interests: telecommunication networks, interconnection, network optimization, simulation.

Snezana MLADENOVIC. PhD in Informatics, Associated Professor, Department of Mathematics, Faculty of Transport and Traffic Engineering, University of Belgrade, Serbia. Research interests: information technologies, simulation, development and optimization of software systems.

Vladanka AĆIMOVIĆ-RASPOPOVIĆ. PhD in Telecommunication traffic and networks, Professor, Department of Telecommunication traffic and networks, Faculty of Transport and Traffic Engineering, University of Belgrade, Serbia. Research interests: telecommunication networks, interconnection, network optimization, simulation, telecommunication pricing. 